TITLE:

\title{
Impact of cumulative steroid dose on infectious diseases after allogenic hematopoietic stem cell transplantation
}

\section{$\operatorname{AUTHOR}(\mathrm{S}):$}

Watanabe, Mizuki; Kanda, Junya; Hishizawa, Masakatsu; Kondo, Tadakazu; Yamashita, Kouhei; Takaori-Kondo, Akifumi

\section{CITATION:}

Watanabe, Mizuki ...[et al]. Impact of cumulative steroid dose on infectious diseases after allogenic hematopoietic stem cell transplantation. Transplant Infectious Disease 2019, 21(2): e13049.

\section{ISSUE DATE:}

2019-04

URL:

http://hdl.handle.net/2433/240763

\section{RIGHT:}

This is the peer reviewed version of the following article: Watanabe, M, Kanda, J, Hishizawa, M, Kondo, T, Yamashita, K, Takaori - Kondo, A. Impact of cumulative steroid dose on infectious diseases after allogenic hematopoietic stem cell transplantation. Transpl Infect Dis. 2019; 21:e13049., which has been published in final form at

https://doi.org/10.1111/tid.13049. This article may be used for non-commercial purposes in accordance with Wiley Terms and Conditions for Use of Self-Archived Versions.; The full-text file will be made open to the public on 5 April 2020 in accordance with publisher's 'Terms and Conditions for Self-Archiving'; この論文は出版社版でありません。引用の際 には出版社版をご確認ご利用ください。; This is not the published version. Please cite only the published version. 
Watanabe, et al. Impact of cumulative steroid on infections after allo-SCT

\section{Impact of cumulative steroid dose on infectious diseases after allogenic hematopoietic stem cell transplantation}

Mizuki Watanabe ${ }^{1}$, Junya Kanda1, Masakatsu Hishizawa1, Tadakazu Kondo, Kouhei Yamashita ${ }^{1}$, Akifumi Takaori-Kondo ${ }^{1}$

6

${ }^{1}$ Department of Hematology and Oncology, Graduate School of Medicine, Kyoto

8 University, Kyoto, Japan

9

10

\section{Conflict-of-interest disclosure}

12

13

The authors declare no competing financial interests \\ 14 Abstract}

Systemic steroid is used to treat various transplant-related complications after allogenic hematopoietic stem cell transplantation (allo-HSCT). However, measures to evaluate its impact on infections are still limited. Hence, we examined the cumulative steroid dose used within 30 days after transplant as a predictor of future risk of infections. This study included 226 patients who underwent their first allo-HSCT at Kyoto University Hospital between 2005 and 2015. Sixty-one patients received transplantation from related donors, 106 received unrelated BMT and 59 received unrelated single-unit CBT. Patients were categorized into 3 groups according to the cumulative steroid dose in terms of prednisolone: no-steroid group ( $n=174)$, low-dose group $(<=7 \mathrm{mg} / \mathrm{kg})(\mathrm{n}=22)$ and high-dose group $(>7 \mathrm{mg} / \mathrm{kg})(\mathrm{n}=30)$. In a multivariate analysis, high-dose steroid administration was associated with CMV antigenemia (HR 1.91, $\mathrm{P}=0.037)$ and bacteremia (HR 2.59, $\mathrm{P}=0.053)$. No impact was found on the occurrence of invasive fungal infection. In conclusion, high-dose cumulative steroid could predict high risks of bacteremia and CMV antigenemia. Additional anti-bacterial agents for fever and regular measurement of CMV antigen are recommended for whom with systemic steroid administration even after neutrophil engraftment.

Text word count; abstract word count, 182; tables, 3; figures, 3; supplemental tables, 0 
Watanabe, et al. Impact of cumulative steroid on infections after allo-SCT

\section{Introduction}

2 Systemic steroid is frequently used as a primary treatment for transplant-related

3 complications such as graft-versus-host disease (GVHD) and non-infectious

4 pulmonary complications after allogeneic hematopoietic stem cell

5 transplantation $(\mathrm{HSCT})^{1-3}$. The use of systemic steroid along with the

6 occurrence of GVHD has been suggested to be a risk factor for various

7 infectious diseases ${ }^{4-8}$, which are main causes of transplant-related mortality.

8 Since the number of HSCTs with a higher risk of complications, such as cord

9 blood transplantations (CBT) and HLA mismatch transplantations in older

10 patients, has been increasing ${ }^{9-12}$, it is important to evaluate the effect of steroid

11 use on clinical outcomes.

12

13 The associations between the cumulative dose of steroid and the occurrence of

14 side effects have been discussed in patients with non-hematologic diseases who

15 receive systemic steroid for a prolonged period. The impact of the cumulative

16 dose of steroid on infectious complications has been controversial, although a

17 positive association was noted in patients taking immunosuppressive agents

18 after solid organ transplantations ${ }^{13-16}$. Similarly, in recipients of HSCT, steroid

19 administration could increase the risk of infectious complications because of the

20 concomitant use of calcineurin inhibitors and the delay of immune reconstitution

21 after HSCT. However, there is little information available regarding the steroid 22 dose. Hence, in the present study, we examined the impact of the cumulative 23 steroid dose on the risk of infectious diseases after HSCT in a single transplant 24 center. 
Watanabe, et al. Impact of cumulative steroid on infections after allo-SCT

\section{Methods}

\section{Data collection}

3 A total of 238 patients who underwent their first allogeneic HSCT for hematologic

4 diseases at Kyoto University Hospital from 2005 to 2015 and survived at least 30

5 days after transplantation were included. Patients who had already started to

6 receive steroid before transplantation were excluded. Patients who had active

7 bacterial, fungal, or viral infection at transplantation or who had had history of

8 invasive fungal infection before transplantation were also excluded. The

9 Institutional Review Board of Kyoto University Hospital, where this study was

10 organized, approved this study.

12 Treatment Policy and Definition

13 Definitions

14 Neutrophil engraftment was diagnosed when an absolute neutrophil count over

$15500 / \mu \mathrm{L}$ was observed for 3 days in a row. Acute GVHD was diagnosed and classified by each physician according to traditional criteria ${ }^{17}$.

Invasive fungal infections

$19 \beta D$-glucan was examined once a week, and imaging inspection and blood 20 culture were examined for fever or other suspicious conditions. Diagnoses of 21 invasive fungal infections were categorized into 3 types; possible, probable, and 22 proven, based on the practice guidelines from the Infectious Diseases Society of 23 America (IDSA) and Japanese guidelines ${ }^{18-20}$.

24 In our hospital, antifungal prophylaxis was administered in all patients who 25 underwent allo-HSCT. The antifungal agents that were generally used as 26 prophylaxis were oral fluconazole, voriconazole, micafungin and liposomal 
Watanabe, et al. Impact of cumulative steroid on infections after allo-SCT

1 amphotericin B injection, according to each patient's history of fungal infection.

2 All patients were hospitalized in a cleanroom of ISO Class 5 (ISO 14644-1) ${ }^{21}$

3 before and in the early period after day0 and moved to a cleanroom of ISO Class

46 (ISO 14644-1) 21 after they achieved neutrophil engraftment.

5

\section{$6 \quad$ CMV antigenemia and CMV disease}

7 CMVpp65 antigen examinations were performed using $\mathrm{C} 10 / 11^{22}$ method or

8 C7-HRP23 method once a week for every patient after transplantation and

9 examined additionally for suspicious symptoms of CMV diseases.

10 In cases with more than 3 positive cells in 2 slides (C10/C11 method) or more

11 than 2 positive cells out of 50000 WBC (C7-HRP method), pre-emptive therapy

12 was given followed by close CMV-antigen monitoring ${ }^{22,23}$. Diagnosis of CMV

13 end-organ diseases were diagnosed according to published definitions ${ }^{24}$.

\section{Other viremias}

16 Patients were examined by viral PCR detection at the timing of fever of unknown

17 origin or any other symptoms of infection based on the judgment of each 18 physician in charge. Viruses examined in PCR included adenovirus, BK virus, 19 JC virus, varicella zoster virus, human herpes simplex, EB virus and other 20 viruses according to each patient's symptoms.

Bacteremia

23 Two sets of blood culture were examined for each patient with fever or any other 24 symptoms suggesting infectious diseases. As our policy, antibacterial 25 prophylaxis was not applied in every patient, except for those who were at high risk of bacterial infection, such as those with a history of repeated severe 
Watanabe, et al. Impact of cumulative steroid on infections after allo-SCT

1 bacterial infection or a long history of chemotherapeutic treatment.

2

\section{Endpoints}

4 The endpoint of this study was the incidence of various infectious diseases

5 including invasive fungal infection, cytomegalovirus (CMV) antigenemia, and

6 bacteremia diagnosed from 30 days to 6 months after HSCT. The cumulative

7 steroid dose was calculated as the total amount administered per patient within

830 days after transplantation, since the first steroid administration mainly began

9 within this period as a treatment for pre-engraftment or engraftment syndrome 10 and for acute GVHD.

\section{Statistical analysis}

13 Descriptive statistics were used to summarize variables related to patient 14 characteristics. We calculated the cumulative steroid dose within 30 days after 15 HSCT. The landmark day was set at 30 days after transplantation. 16 Prednisolone-equivalent conversion was performed in accordance to the general 17 formula ${ }^{25}$. Episodes of infectious diseases (invasive fungal infection, CMV 18 antigenemia or disease, and bacteremia) were calculated based on cumulative 19 incidence curves. A competing event was death without infectious disease. 20 Cumulative incidences in the groups were compared using the Gray test. Fine 21 and Gray's proportional hazards model was used to evaluate the effect of 22 cumulative steroid dose on the occurrence of infectious diseases ${ }^{26}$. The following covariates were considered; recipient's sex, age ( $<50$ or $\geq 50$ years 24 old), disease diagnosis (myeloid malignancies, lymphoid malignancies, or 25 others), year of transplantation (2005-2009 or 2010-2016), disease status 26 (complete remission $[\mathrm{CR}]$ or non-CR), donor type (bone marrow transplantation 
Watanabe, et al. Impact of cumulative steroid on infections after allo-SCT

1 from unrelated donor, peripheral blood stem cell transplantation from related 2 donor, or CBT), conditioning regimen (reduced-intensity or myeloablative), 3 GVHD prophylaxis (tacrolimus or cyclosporine in addition to mycophenolate 4 mofetil or methotrexate), presence or absence of neutrophil engraftment at day 530 , and prophylactic administration of levofloxacin. All factors, in addition to the 6 main effect, were selected with a variable retention criterion of $P<0.05$ in the 7 univariate analysis and analyzed in the multivariate analysis.

8 Although acute GVHD has been suggested to be a risk factor for infectious

9 diseases after HSCT, we did not include acute GVHD because there was a 10 correlation between acute GVHD and steroid administration (data not shown), 11 and it would be inappropriate to include both in the same model.

12 All statistical analyses were performed with Stata version 14 (Stata Corp,

13 College Station, TX) and EZR (Saitama Medical Center, Jichi Medical University, 14 Saitama, Japan), which is a graphical user interface for R (The R Foundation for 15 Statistical Computing, version 3.1.1, Vienna, Austria). 
Watanabe, et al. Impact of cumulative steroid on infections after allo-SCT

\section{Results}

\section{Patient characteristics}

3 Sixty-one patients received transplantation from a related donor, 106 received 4 unrelated bone marrow grafts, and 59 received unrelated cord blood units. Their 5 median age was 51 years (range, 17-66). Neutrophil engraftment was achieved 6 in 203 patients $(90 \%)$ by day 30 and mean neutrophil engraftment day from 7 transplantation in each graft were 21 in bone marrow transplantation, 17 in 8 peripheral blood stem cell transplantation and 25 in cord blood transplantation.

9 Patients were categorized into 3 groups according to the cumulative steroid 10 dose within 30 days: no steroid group $(n=174)$, low-dose cumulative steroid 11 group $(7 \mathrm{mg} / \mathrm{kg}$ or less of prednisolone-equivalent dose, $\mathrm{n}=22)$, and high-dose cumulative steroid group (over $7 \mathrm{mg} / \mathrm{kg}$ of prednisolone-equivalent dose, $\mathrm{n}=30$ ).

13 The cutoff value of $7 \mathrm{mg} / \mathrm{kg}$ of prednisolone-equivalent dose approximately 14 stands for initial steroid treatment against acute GVHD in Japan $(1 \mathrm{mg} / \mathrm{kg}$ during 157 days at maximum). The reason for steroid administration was treatment for 16 GVHD in 33 patients, engraftment syndrome in 9, and other reasons including 17 lung complications in 10. Grade II to IV acute GVHD was diagnosed in 96 patients in total. There was no obvious difference in background among the different donor sources. (Table 1).

\section{Invasive fungal infection}

We observed 13 cases of invasive fungal infection, including one proven case with candida bloodstream infection and 2 probable and 10 possible cases of pneumonia. The cumulative incidence of invasive fungal infection at 6 months was $5.7 \%, 4.5 \%$, and $6.7 \%$ in the no-administration, low-dose, and high-dose groups, respectively $(P=0.231$, Gray test) (Figure 1$)$. Multivariate analysis 
Watanabe, et al. Impact of cumulative steroid on infections after allo-SCT

1 showed no association between steroid administration and the occurrence of

2 invasive fungal infection. We found no other significant risk factor.

$4 \quad$ CMV antigenemia and diseases

5 Eighty-six HSCT were performed from CMV-antibody (Ab) positive donors to

6 CMV-Ab positive recipients, 10 were from CMV-Ab positive donors to CMV

7 negative recipients and the other 103 were from CMV-Ab negative donors 8 (Table 1).

9 A total of $105(46 \%)$ patients were diagnosed as CMV antigenemia and 81 $10(78 \%)$ received Ganciclovir as a pre-emptive antiviral therapy. Seven patients 11 were pathologically diagnosed as CMV disease including colitis and hepatitis, all 12 of whom were positive for CMV antigenemia. There were 4 cases of CMV 13 antigenemia with clinically suspected CMV diseases, although they were not 14 definitely diagnosed due to a lack of pathological evidence. No patient died of 15 CMV-related complications. The cumulative incidences of CMV antigenemia at 6 months in the no-administration, low-dose, and high-dose groups were $49.7 \%$,

$1768.8 \%$, and $69.6 \%$, respectively $(P=0.038)$ (Figure 2$)$. Reason for steroid 18 initiation had little impact on the occurrence of CMV antigenemia (GVHD vs 19 other reasons: HR 2.119, $\mathrm{P}=0.089)$. Multivariate analysis showed that both a 20 low-dose and high-dose of cumulative steroid administration were associated 21 with CMV reactivation, although the association in the low-dose group was not statistically significant (low-dose vs. no-administration group: HR 1.64, P=0.100, high-dose vs. no-administration group: HR $1.91 \mathrm{P}=0.037)$. Other risk factors 24 detected were cord blood unit as a donor source (cord blood unit vs. sibling donor: $\mathrm{HR}$ 1.62, $\mathrm{P}=0.018$ ) and recipient age over 50 years at transplantation (age >=50 vs. <50: HR 1.62, $\mathrm{P}=0.007$ ) (Table 2). 
Watanabe, et al. Impact of cumulative steroid on infections after allo-SCT

1

\section{Viral infections other than CMV}

3 A total of 15 cases were diagnosed as viremia including Adenovirus in 1 patient,

4 BK virus in 2, Epstein Barr virus in 1, Varicella Zoster virus in 3, and human

5 herpes virus 6 in 7 . Ten patients were in the no-administration group and there

6 was no association between viremia and the cumulative steroid dose.

7

$8 \quad$ Bacteremia

9 The cumulative incidences of bacteremia at 6 months in the no-administration,

10 low-dose, and high-dose groups were $9.3 \%, 15.8 \%$, and $21.7 \%$, respectively $(P=$ $110.224)$ (Figure 3). Detected microbes at the first onset of bacteremia were 12 gram-negative rods in 15 cases, gram-positive cocci in 7 cases, and 13 gram-positive rods in 1 case. Reason for steroid initiation had little impact on the 14 occurrence of bacteremia (GVHD vs other reasons: HR 4.89, $\mathrm{P}=0.14$ ). 15 Administration of levofloxacin showed no apparent prophylactic effect on 16 bacteremia (HR $0.73, P=0.574)$.

17 Multivariate analysis showed that the high-dose group was marginally 18 associated with an increased risk of bacteremia (low-dose vs. no-administration 19 group: HR 2.13, P =0.240, high-dose vs. no-administration group: $\mathrm{HR} 2.59, \mathrm{P}=$ 20 0.053). Regarding the microbes detected, there was no significant difference 21 among the three groups. The other major risk factor for bacteremia was a vs. $<50: \mathrm{P}=0.021)($ Table 3$)$.

\section{Other bacterial infections}

26 The other infectious events proven as bacterial complications were 4 cases 
Watanabe, et al. Impact of cumulative steroid on infections after allo-SCT

1 Clostridium difficile colitis, 2 cases of pneumonia (1 of Pseudomonas 2 aeruginosa, 1 of Stenotrophomonas maltophilia), 1 cellulitis of 3 Coagulase-negative staphylococcus, and 1 endophthalmitis of 4 Coagulase-negative staphylococcus. 
Watanabe, et al. Impact of cumulative steroid on infections after allo-SCT

\section{Discussion}

2 In the present study, we examined the impact of the cumulative dose of steroid

3 on infectious complications after HSCT and found associations between steroid

4 dose and both CMV and bacterial infections following HSCT.

5

6 Although acute GVHD and systemic steroid have been reported to be risk 7 factors for invasive fungal infection after $\mathrm{HSCT}^{27-30}$, the cumulative steroid dose 8 was not associated with fungal infection in our study. All patients in our hospital

9 continued prophylactic treatment with antifungal drugs according to the risk of 10 fungal infection, following Japanese and European guidelines ${ }^{31}$. Only 13 of 226 11 patients had invasive fungal infection over 10 years, although our cohort 12 included a relatively large number of cord blood transplantations. This suggests 13 that fungal infection could be avoided regardless of the occurrence of acute 14 GVHD, steroid use, and donor source by appropriate clinical practice.

With regard to CMV-related complications, steroid use was strongly associated with CMV antigenemia regardless of the cumulative dose, which is similar to previous reports $4,32,33$. Almost all the patients in our cohort were seropositive before transplant and thus CMV antigen levels must be measured regularly after HSCT. Another risk factor for CMV antigenemia was cord blood unit as a donor source, although the HR was lower than previously reported and there were no CMV-related deaths. Older patients also had a higher risk of CMV antigenemia. Contrary to a previous report ${ }^{4}$, myeloablative conditioning was not found to be a risk factor for CMV antigenemia, which is probably due to the difference in the conditioning regimen or the medication used for GVHD prophylaxis. 
Watanabe, et al. Impact of cumulative steroid on infections after allo-SCT

1 High-dose, but not low-dose, cumulative steroid administration was a risk factor

2 for bacterial infection. Anti-bacterial prophylaxis and preemptive therapies for

3 fever of undetected origin might be better considered for patients after HSCT

4 receiving a high cumulative dose of steroid, regardless of their neutrophil count.

5 An advanced age at transplant was another risk factor for bacterial infection after

6 HSCT, which was consistent with previous reports ${ }^{34}$.

7

8 The present study has several limitations. First, this is a retrospective study of

9 small population with heterogeneous background in a single transplant center.

10 Second, the loads of viruses other than CMV were not regularly measured and

11 the timing of the examination was determined by each physician in charge.

12 Finally, information on blood sugar levels was not collected, although blood

13 sugar levels were checked regularly and treated by continuous intravenous

14 insulin infusion, which minimized the effect of hyperglycemia on bacterial

15 infections.

16

17 In conclusion, our study confirmed that the cumulative steroid dose could be a 18 good prognostic marker for CMV antigenemia and bacterial infection after 19 HSCT. These post-transplant complications must be detected and managed in 20 the early period, particularly in elderly patients who are receiving a high 21 cumulative dose of steroid.

23 ACKNOWLEDGEMENTS

24 We are grateful to Emi Furusaka, Tomoko Okuda and Megumi Oka for their 25 expert data-management and secretarial assistance, and to all the members of 26 the transplant teams at Kyoto University Hospital for their dedicated care of the 
Watanabe, et al. Impact of cumulative steroid on infections after allo-SCT

1 patients and donors.

2 This work was supported in part by the Takeda Science Foundation (JK). 
Watanabe, et al. Impact of cumulative steroid on infections after allo-SCT

\section{Reference}

2 1. Jamil MO, Mineishi S. State-of-the-art acute and chronic GVHD treatment. Int J Hematol. 2015;101(5):452-466. doi:10.1007/s12185-015-1785-1

2. Sung AD, Chao NJ. Concise Review: Acute Graft-Versus-Host Disease: Immunobiology, Prevention, and Treatment. Stem Cells Transl Med. 2013;2(1):25-32. doi:10.5966/sctm.2012-0115

3. Magenau J, Reddy P. Next generation treatment of acute graft-versus-host disease. Leukemia. 2014;28(12):2283-2291. doi:10.1038/leu.2014.195

4. Cohen L, Yeshurun M, Shpilberg O, Ram R. Risk factors and prognostic scale for cytomegalovirus (CMV) infection in CMV-seropositive patients after allogeneic hematopoietic cell transplantation. Transpl Infect Dis. 2015;17(4):510-517. doi:10.1111/tid.12398

5. Faraci M, Lanino E, Morreale G, et al. Bacteremias and invasive fungal diseases in children receiving etanercept for steroid-resistant acute GVHD. Bone Marrow Transplant. 2011. doi:10.1038/bmt.2010.80

6. Greco R, Crucitti L, Noviello M, et al. Human Herpesvirus 6 Infection Following Haploidentical Transplantation: Immune Recovery and Outcome. Biol Blood Marrow Transplant. 2016. doi:10.1016/j.bbmt.2016.09.018

7. Mihu CN, Schaub J, Kesh S, et al. Risk Factors for Late Staphylococcus Aureus Bacteremia after Allogeneic Hematopoietic Stem Cell Transplantation: A Single-Institution, Nested Case-Controlled Study. Biol Blood Marrow Transpl. 2008;14:1429-1433. doi:10.1016/j.bbmt.2008.09.005 
Watanabe, et al. Impact of cumulative steroid on infections after allo-SCT

who underwent hematopoietic stem cell transplantation at a single center: A retrospective study of the risk factors. Pediatr Transplant. 2009;13(7):898-905. doi:10.1111/j.1399-3046.2008.01084.x

9. Sawada A, Inoue M, Koyama-Sato M, et al. Umbilical cord blood as an alternative source of reduced-intensity hematopoietic stem cell transplantation for chronic epstein-barr virus-associated T or natural killer cell lymphoproliferative diseases. Biol Blood Marrow Transplant. 2014;20(2):214-221. doi:10.1016/j.bbmt.2013.10.026

10. Anasetti C. Use of alternative donors for allogeneic stem cell transplantation. Hematology Am Soc Hematol Educ Program. 2015;2015(1):220-224. doi:10.1182/asheducation-2015.1.220

11. Lorentino F, Labopin M, Fleischhauer $\mathrm{K}$, et al. The impact of HLA matching on outcomes of unmanipulated haploidentical HSCT is modulated by GVHD prophylaxis. Blood Adv. 2017;1(11):669-680. doi:10.1182/bloodadvances.2017006429

12. Hambach L, Stadler M, Dammann E, Ganser A, Hertenstein B. Increased risk of complicated CMV infection with the use of mycophenolate mofetil in allogeneic stem cell transplantation. Bone Marrow Transpl. 2002;29(11):903-906. doi:10.1038/sj.bmt.1703583

13. Del Rinc??n I, Battafarano DF, Restrepo JF, Erikson JM, Escalante A. Glucocorticoid dose thresholds associated with all-cause and cardiovascular mortality in rheumatoid arthritis. Arthritis Rheumatol. 2014. doi:10.1002/art.38210

14. Dixon WG, Kezouh A, Bernatsky S, Suissa S. The influence of systemic glucocorticoid therapy upon the risk of non-serious infection in older patients with rheumatoid arthritis: A nested case-control study. Ann 
Watanabe, et al. Impact of cumulative steroid on infections after allo-SCT

Rheum Dis. 2011;70(6):956-960. doi:10.1136/ard.2010.144741

15. STANBURY RM, GRAHAM EM. Systemic corticosteroid therapy---side effects and their management. Br J Ophthalmol. 1998;82(6):704-708. doi:10.1136/bjo.82.6.704

16. Opelz G, D??hler B. Association between steroid dosage and death with a functioning graft after kidney transplantation. Am J Transplant. 2013;13(8):2096-2105. doi:10.1111/ajt.12313

17. Przepiorka D, DJ W, Martin P, et al. 1994 Consensus Conference on Acute GvHD Grading. Vol 15.; 1995.

18. Patterson TF, Thompson GR, Denning DW, et al. Practice guidelines for the diagnosis and management of aspergillosis: 2016 update by the infectious diseases society of America. Clin Infect Dis. 2016;63(4):e1-e60. doi:10.1093/cid/ciw326

19. Pappas PG, Kauffman CA, Andes DR, et al. Clinical Practice Guideline for the Management of Candidiasis: 2016 Update by the Infectious Diseases Society of America. Clin Infect Dis. 2015;62(4):e1-e50. doi:10.1093/cid/civ933

20. De Pauw B, Walsh TJ, Donnelly JP, et al. Revised Definitions of Invasive Fungal Disease from the European Organization for Research and Treatment of Cancer/Invasive Fungal Infections Cooperative Group and the National Institute of Allergy and Infectious Diseases Mycoses Study Group (EORTC/MSG) C. Clin Infect Dis. 2008;46(12):1813-1821. doi:10.1086/588660

21. INTERNATIONAL STANDARD. 2016;2015.

22. Mori T, Okamoto S, Matsuoka S, et al. Risk-adapted pre-emptive therapy for cytomegalovirus disease in patients undergoing allogeneic bone 
Watanabe, et al. Impact of cumulative steroid on infections after allo-SCT

marrow transplantation. 2000;(August 1999):765-769.

23. Kanda Y, Mineishi S, Saito T, et al. Pre-emptive therapy against cytomegalovirus (CMV) disease guided by CMV antigenemia assay after allogeneic hematopoietic stem cell transplantation: A single-center experience in Japan. Bone Marrow Transplant. 2001;27(4):437-444. doi:10.1038/sj.bmt. 1702805

24. Ljungman $P$, Griffiths $P$, Paya $C$. Definitions of Cytomegalovirus Infection and Disease in Transplant Recipients. 2002;34.

25. Casavant MJ. Goodman and Gilman's The Pharmacological Basis of Therapeutics. Vol 288. 13th ed. (Laurence L. Brunton, PhDBruce A. Chabner BCK, ed.).; 2002. doi:10.1001/jama.288.16.2052

26. Fine JP, Gray RJ, Fine JP, Gray RJ. A Proportional Hazards Model for the Subdistribution of a Competing Risk Stable URL :

http://www.jstor.org/stable/2670170 All use subject to http://about.jstor.org/terms A Proportional Hazards Model for the Subdistribution of a Competing Risk. 1999;94(446):496-509.

27. Liu Y-C, Chien S-H, Fan N-W, et al. Incidence and risk factors of probable and proven invasive fungal infection in adult patients receiving allogeneic hematopoietic stem cell transplantation. J Microbiol Immunol Infect. 2015. doi:10.1016/j.jmii.2015.01.002

28. Miyakoshi S, Kusumi E, Matsumura T, et al. Invasive Fungal Infection Following Reduced-Intensity Cord Blood Transplantation for Adult Patients with Hematologic Diseases. Biol Blood Marrow Transplant. 2007;13(7):771-777. doi:10.1016/j.bbmt.2007.02.012

29. Mielcarek M, Storer BE, Boeckh M, et al. Initial therapy of acute graft-versus-host disease with low-dose prednisone does not compromise 
Watanabe, et al. Impact of cumulative steroid on infections after allo-SCT

patient outcomes. Blood. 2009. doi:10.1182/blood-2008-07-168401

30. Matsumura-Kimoto $\mathrm{Y}$, Inamoto $\mathrm{Y}$, Tajima K, et al. Association of Cumulative Steroid Dose with Risk of Infection after Treatment for Severe Acute Graft-versus-Host Disease. Biol Blood Marrow Transplant. 2016. doi:10.1016/j.bbmt.2016.02.020

31. Maertens J, Marchetti O, Herbrecht R, et al. European guidelines for antifungal management in leukemia and hematopoietic stem cell transplant recipients: Summary of the ECIL 32009 update. Bone Marrow Transplant. 2011;46(5):709-718. doi:10.1038/bmt.2010.175

32. George B, Kerridge IH, Gilroy N, et al. A risk score for early cytomegalovirus reactivation after allogeneic stem cell transplantation identifies low-, intermediate-, and high-risk groups: Reactivation risk is increased by graft-versus-host disease only in the intermediate-risk group. Transpl Infect Dis. 2012;14(2):141-148.

doi:10.1111/j.1399-3062.2011.00706.x

33. Osarogiagbon RU, Defor TE, Weisdorf MA, Erice A, Weisdorf DJ. CMV antigenemia following bone marrow transplantation: Risk factors and outcomes. Biol Blood Marrow Transplant. 2000;6(3):280-288. doi:10.1016/S1083-8791(00)70010-3

34. Frère $\mathrm{P}$, Baron $\mathrm{F}$, Bonnet $\mathrm{C}$, et al. Infections after allogeneic hematopoietic stem cell transplantation with a nonmyeloablative conditioning regimen. Bone Marrow Transplant. 2006. doi:10.1038/sj.bmt.1705255 
Watanabe, et al. Impact of cumulative steroid on infections after allo-SCT

\section{Figure legends}

2 Figure 1 Cumulative incidence of invasive fungal infection

3 Figure 2 Cumulative incidence of $\mathrm{CMV}$ antigenemia

4 Figure 3 Cumulative incidence of bacteremia 


\begin{tabular}{|c|c|c|c|c|c|c|c|c|c|}
\hline \multirow{2}{*}{\multicolumn{3}{|c|}{$\begin{array}{l}\text { Table1 Patient characteristics } \\
\text { Group by cumulative steroid dose within } 30 \text { days }\end{array}$}} & \multirow{3}{*}{\multicolumn{2}{|c|}{$\begin{array}{l}\text { No administration } \\
\qquad(\mathrm{n}=174) \\
\text { value }\end{array}$}} & \multirow{3}{*}{\multicolumn{2}{|c|}{$\begin{array}{l}\text { Low }(<=7 \mathrm{mg} / \mathrm{kg} \mathrm{PSL}) \\
\qquad(\mathrm{n}=22) \\
\text { value }\end{array}$}} & \multirow{3}{*}{\multicolumn{2}{|c|}{$\begin{array}{l}\text { High }(>7 \mathrm{mg} / \mathrm{kg} \mathrm{PSL}) \\
\qquad(\mathrm{n}=30) \\
\text { value }\end{array}$}} & \multirow{4}{*}{$\begin{array}{l}\text { Variance } \\
\text { P-Value }\end{array}$} \\
\hline & & & & & & & & & \\
\hline & & \multirow{2}{*}{$\begin{array}{c}\text { Total } \\
\mathrm{n}^{* 1}\end{array}$} & & & & & & & \\
\hline & & & $\mathrm{n}$ & $\%^{* 2}$ & $\mathrm{n}$ & $\%$ & $n$ & $\%$ & \\
\hline \multicolumn{2}{|c|}{$\mathrm{Age}^{* 3}$ median(range) } & & $51(17-66)$ & & $47(21-66)$ & & $48(20-66)$ & & 0.651 \\
\hline \multirow{2}{*}{ Gender } & Male & 126 & 103 & 59.2 & 9 & 40.9 & 14 & 46.7 & \multirow{2}{*}{0.144} \\
\hline & Female & 100 & 71 & 40.8 & 13 & 59.1 & 16 & 53.3 & \\
\hline \multirow{3}{*}{ Donor source } & Sibling & 61 & 47 & 27.0 & 7 & 31.8 & 7 & 23.3 & \multirow{3}{*}{0.930} \\
\hline & Unrelated BM & 106 & 81 & 46.6 & 9 & 40.9 & 16 & 53.3 & \\
\hline & Unrelated CB & 59 & 46 & 26.4 & 6 & 27.3 & 7 & 23.3 & \\
\hline \multirow{4}{*}{ Disease } & AML/MDS & 134 & 113 & 64.9 & 11 & 50.0 & 10 & 33.3 & \multirow{4}{*}{0.015} \\
\hline & ALL/other leukemias & 50 & 30 & 17.2 & 8 & 36.4 & 12 & 40.0 & \\
\hline & Malignant lymphoma & 35 & 25 & 14.4 & 3 & 13.6 & 7 & 23.3 & \\
\hline & Aplastic anemia & 7 & 6 & 3.4 & 0 & 0.0 & 1 & 3.3 & \\
\hline \multirow{2}{*}{ Disease status } & CR & 94 & 72 & 41.4 & 11 & 50.0 & 11 & 36.7 & \multirow{2}{*}{0.652} \\
\hline & non CR & 132 & 102 & 58.6 & 11 & 50.0 & 19 & 63.3 & \\
\hline \multirow{2}{*}{ Conditioning intensity } & Myeloablative & 112 & 86 & 49.4 & 11 & 50.0 & 15 & 50.0 & \multirow{2}{*}{1.000} \\
\hline & Reduced intensity & 114 & 88 & 50.6 & 11 & 50.0 & 15 & 50.0 & \\
\hline Neutrophil & No & 20 & 18 & 10.5 & 1 & 4.5 & 1 & 3.4 & 0.477 \\
\hline engraftment at Day30 & Yes & 203 & 154 & 89.5 & 21 & 95.5 & 28 & 96.6 & \\
\hline
\end{tabular}




\begin{tabular}{|c|c|c|c|c|c|c|c|c|c|}
\hline levofloxacin & NO & 181 & 142 & 84.0 & 14 & 63.6 & 25 & 89.3 & 0.079 \\
\hline prophylaxis & Yes & 38 & 27 & 16.0 & 8 & 36.4 & 3 & 10.7 & \\
\hline \multirow{4}{*}{ GVHD prophylaxis } & $\mathrm{Cl}$ & 19 & 12 & 6.9 & 2 & 9.1 & 5 & 16.7 & \multirow{4}{*}{0.755} \\
\hline & $\mathrm{Cl}+\mathrm{MMF}$ & 35 & 27 & 15.5 & 4 & 18.2 & 4 & 13.3 & \\
\hline & $\mathrm{Cl}+\mathrm{MTX}$ & 137 & 107 & 61.5 & 13 & 59.1 & 17 & 56.7 & \\
\hline & $\mathrm{Cl}+\mathrm{MMF}+\mathrm{MTX}$ & 35 & 28 & 16.1 & 3 & 13.6 & 4 & 13.3 & \\
\hline \multirow{4}{*}{$\begin{array}{c}\text { GVHD grade at } \\
\text { onset }\end{array}$} & 1 & 38 & 30 & 34.5 & 6 & 30.0 & 2 & 7.4 & \multirow{4}{*}{0.092} \\
\hline & II & 76 & 47 & 54.0 & 11 & 55.0 & 18 & 66.7 & \\
\hline & III & 14 & 6 & 6.9 & 2 & 10.0 & 6 & 22.2 & \\
\hline & IV & 6 & 4 & 4.6 & 1 & 5.0 & 1 & 3.7 & \\
\hline \multirow[t]{4}{*}{ CMV resopositivity } & Donor+/ Recipient+ & 86 & 63 & 41.2 & 9 & 45.0 & 14 & 53.8 & \multirow{4}{*}{0.527} \\
\hline & Donor+/ Recipient- & 10 & 9 & 5.9 & 0 & 0.0 & 1 & 3.8 & \\
\hline & Donor-/ Recipient+ & 85 & 64 & 41.8 & 10 & 50.0 & 11 & 42.3 & \\
\hline & Donor-/ Recipient- & 18 & 17 & 11.1 & 1 & 5.0 & 0 & 0.0 & \\
\hline \multirow{3}{*}{ Reason for steroid } & Acute GVHD & 32 & & & 13 & 59.1 & 19 & 63.3 & \\
\hline & Engraftment syndrome & 9 & & & 3 & 13.6 & 6 & 20.0 & \\
\hline & Others & 11 & & & 6 & 27.3 & 5 & 16.7 & \\
\hline
\end{tabular}

${ }^{*} \mathrm{n}$ indicates the number of patients with each characteristics

${ }^{2} \%$ indicates the percentage of patients in each steroid group

${ }^{*}$ Age indicates patients' age at transplantation

Calcinerin inhibitors include Tacrolimus and Cyclosporin

Abbreviation: AML, acute myeloid leukemia; MDS, myelodysplastic syndrome; ALL, acute lymphoblastic leukemia; CR, complete remission; BM, bone marrow; CB, cord blood; GVHD, graft-versus-host disease; Cl, Calcinerin inhibitor; MMF, mycophenolate mofetil; MTX, methotrexate; PSL, prednisolone 
Table 2 Univariate and multivariate analysis of CMV antigenemia

\begin{tabular}{|c|c|c|c|c|c|c|c|}
\hline \multirow{2}{*}{\multicolumn{2}{|c|}{ Variables }} & \multicolumn{3}{|c|}{ Univariate analysis } & \multicolumn{3}{|c|}{ Multivariate analysis } \\
\hline & & $\mathrm{HR}$ & $95 \% \mathrm{Cl}$ & P-Value & $\mathrm{HR}$ & $95 \% \mathrm{Cl}$ & P-Value \\
\hline \multirow[b]{2}{*}{$\operatorname{Age}^{* 1}$} & $<50$ & 1.00 & & reference & 1.00 & & reference \\
\hline & $\geqq 50$ & 1.46 & $(1.01-2.09)$ & 0.042 & 1.62 & $\begin{array}{l}(1.14- \\
2.30)\end{array}$ & 0.007 \\
\hline Gender & $\begin{array}{c}\text { Male } \\
\text { Female }\end{array}$ & $\begin{array}{l}1.00 \\
0.88\end{array}$ & $(0.60-1.28)$ & $\begin{array}{r}\text { reference } \\
0.499\end{array}$ & & & \\
\hline \multirow{2}{*}{ Year of trasnplant } & $2005-2009$ & 1.00 & & reference & & & \\
\hline & $2010-2015$ & 1.19 & $(0.81-1.74)$ & 0.373 & & & \\
\hline \multirow{3}{*}{ Donor source } & Sibling & 1.00 & & reference & 1.00 & & reference \\
\hline & Unrelated BM & 1.10 & $(0.68-1.78)$ & 0.687 & & & \\
\hline & Unrelated CB & 1.64 & $(1.00-2.68)$ & 0.047 & 1.62 & $\begin{array}{l}(1.09- \\
2.40)\end{array}$ & 0.018 \\
\hline \multirow{4}{*}{ Disease } & AML/MDS & 1.00 & & reference & & & \\
\hline & ALL/other leukemias & 1.43 & $(0.88-2.31)$ & 0.140 & & & \\
\hline & Malignant lymphoma & 0.93 & $(0.50-1.75)$ & 0.824 & & & \\
\hline & Aplastic anemia & 1.46 & $(0.54-3.93)$ & 0.453 & & & \\
\hline \multirow{2}{*}{ Disease status } & CR & 1.00 & & reference & & & \\
\hline & non CR & 1.18 & $(0.80-1.75)$ & 0.394 & & & \\
\hline
\end{tabular}




\begin{tabular}{|c|c|c|c|c|c|c|c|}
\hline \multirow{2}{*}{ Conditioning regimen } & Myeloablative & 1.00 & \multicolumn{2}{|r|}{ reference } & & & \\
\hline & Reduced intensity & 1.19 & $(0.81-1.74)$ & 0.369 & & & \\
\hline \multirow{4}{*}{ GVHD prophylaxis } & $\mathrm{Cl}$ & 1.00 & & reference & & & \\
\hline & $\mathrm{Cl}+\mathrm{MMF}$ & 1.00 & $(0.50-1.99)$ & 0.994 & & & \\
\hline & $\mathrm{Cl}+\mathrm{MTX}$ & 0.65 & $(0.35-1.21)$ & 0.178 & & & \\
\hline & $\mathrm{Cl}+\mathrm{MMF}+\mathrm{MTX}$ & 1.10 & $(0.54-2.22)$ & 0.792 & & & \\
\hline Neutrophil & NO & 1.00 & & & & & \\
\hline engraftment at day30 & Yes & 1.46 & $(0-86-2.50)$ & 0.164 & & & \\
\hline \multirow{3}{*}{ steroid group } & No administration & 1.00 & & reference & 1.00 & & reference \\
\hline & Low-dose ${ }^{* 2}$ & 1.58 & $(0.87-2.87)$ & 0.140 & 1.64 & $\begin{array}{l}(0.91- \\
2.96)\end{array}$ & 0.100 \\
\hline & High-dose ${ }^{* 3}$ & 1.78 & $(1.02-3.12)$ & 0.044 & 1.91 & $\begin{array}{l}(1.04- \\
3.50)\end{array}$ & 0.037 \\
\hline
\end{tabular}

${ }^{* 1}$ Age indicates patients' age at transplantation

${ }^{*}$ Low-dose indicates group who undertook low cumulative dose of steroid ( $<=7 \mathrm{mg} / \mathrm{kg}$ of prednisolone)

${ }^{*} \mathrm{High}$-dose indicates group who undertook high cumulative dose of steroid ( $>7 \mathrm{mg} / \mathrm{kg}$ of prednisolone)

Calcinerin inhibitors include Tacrolimus and Cyclosporin

Abbreviation: HR, hazard ratio; AML, acute myeloid leukemia; MDS, myelodysplastic syndrome; ALL, acute

lymphoblastic leukemia; CR, complete remission; BM, bone marow; CB, cord blood; GVHD, graft-versus-host disease;

$\mathrm{Cl}$, Calcinerin inhibitor; MMF, mycophenolate mofetil; MTX, methotrexate; PSL, prednisolone 
Table $3 \quad$ Univariate and multivariate analysis of bacteremia

\begin{tabular}{|c|c|c|c|c|c|c|c|}
\hline \multirow{2}{*}{\multicolumn{2}{|c|}{ Variables }} & \multicolumn{3}{|c|}{ Univariate analysis } & \multicolumn{3}{|c|}{ Multivariate analysis } \\
\hline & & $\mathrm{HR}$ & $95 \% \mathrm{Cl}$ & P-Value & $\mathrm{HR}$ & $95 \% \mathrm{Cl}$ & P-Value \\
\hline \multirow{2}{*}{$\operatorname{Age}^{* 1}$} & $<50$ & 1.00 & & reference & 1.00 & & reference \\
\hline & $\geqq 50$ & 2.40 & $(1.07-5.38)$ & 0.034 & 2.69 & $(1.16-6.22)$ & 0.021 \\
\hline \multirow{2}{*}{ Gender } & Male & 1.00 & & reference & & & \\
\hline & Female & 1.20 & $(0.52-2.78)$ & 0.671 & & & \\
\hline \multirow{2}{*}{ Year of trasnplant } & $2005-2009$ & 1.00 & & reference & & & \\
\hline & $2010-2015$ & 1.11 & $(0.48-2.53)$ & 0.813 & & & \\
\hline \multirow{3}{*}{ Donor source } & Sibling & 1.00 & & reference & & & \\
\hline & Unrelated BM & 1.28 & $(0.46-3.55)$ & 0.633 & & & \\
\hline & Unrelated CB & 1.18 & $(0.37-3.72)$ & 0.778 & & & \\
\hline \multirow{4}{*}{ Disease } & AML/MDS & 1.00 & & reference & & & \\
\hline & ALL/other leukemias & 1.06 & $(0.36-2.77)$ & 0.917 & & & \\
\hline & Malignant lymphoma & 1.52 & $(0.52-3.96)$ & 0.419 & & & \\
\hline & Aplastic anemia & & & & & & \\
\hline \multirow{2}{*}{ Disease status } & $\mathrm{CR}$ & 1.00 & & reference & & & \\
\hline & non CR & 1.63 & $(0.66-3.98)$ & 0.287 & & & \\
\hline \multirow{2}{*}{ Conditioning regimen } & Myeloablative & 1.00 & & reference & & & \\
\hline & Reduced intensity & 1.70 & $(0.72-4.03)$ & 0.226 & & & \\
\hline
\end{tabular}




\begin{tabular}{|c|c|c|c|c|c|c|c|}
\hline \multirow{4}{*}{ GVHD prophylaxis } & $\mathrm{Cl}$ & 1.00 & & reference & & & \\
\hline & $\mathrm{Cl}+\mathrm{MMF}$ & 1.61 & $(0.31-9.13)$ & 0.568 & & & \\
\hline & $\mathrm{Cl}+\mathrm{MTX}$ & 0.72 & $(0.15-3.37)$ & 0.674 & & & \\
\hline & $\mathrm{Cl}+\mathrm{MMF}+\mathrm{MTX}$ & 1.16 & $(0.24-6.58)$ & 0.864 & & & \\
\hline Neutrophil & NO & 1.00 & & & & & \\
\hline engraftment at day30 & Yes & 3.86 & $(0.23-64.05)$ & 0.346 & & & \\
\hline Levofloxacin & NO & 1.00 & & & & & \\
\hline \multirow[t]{2}{*}{ prophylaxis } & Yes & 0.73 & $(0.250-2.159)$ & 0.574 & & & \\
\hline & No administration & 1.00 & & reference & 1.00 & & reference \\
\hline \multirow[t]{2}{*}{ steroid group } & Low-dose ${ }^{* 2}$ & 1.74 & $(0.50-6.07)$ & 0.390 & 2.13 & $(0.60-7.51)$ & 0.240 \\
\hline & High-dose $^{\star 3}$ & 2.27 & $(0.87-5.93)$ & 0.097 & 2.59 & $(0.99-6.78)$ & 0.053 \\
\hline
\end{tabular}

${ }^{*}$ Age indicates patients' age at transplantation

${ }^{*}$ Low-dose indicates group who undertook low cumulative dose of steroid $(<=7 \mathrm{mg} / \mathrm{kg}$ of prednisolone)

${ }^{*} \mathrm{High}$-dose indicates group who undertook high cumulative dose of steroid $(>7 \mathrm{mg} / \mathrm{kg}$ of prednisolone)

Calcinerin inhibitors include Tacrolimus and Cyclosporin

Abbreviation: HR, hazard ratio; AML, acute myeloid leukemia; MDS, myelodysplastic syndrome; ALL, acute lymphoblastic leukemia; $\mathrm{CR}$, complete remission; $\mathrm{BM}$, bone marow; $\mathrm{CB}$, cord blood; GVHD, graft-versus-host disease; $\mathrm{Cl}$, Calcinerin inhibitor; MMF, mycophenolate mofetil; MTX, methotrexate; PSL, prednisolone 


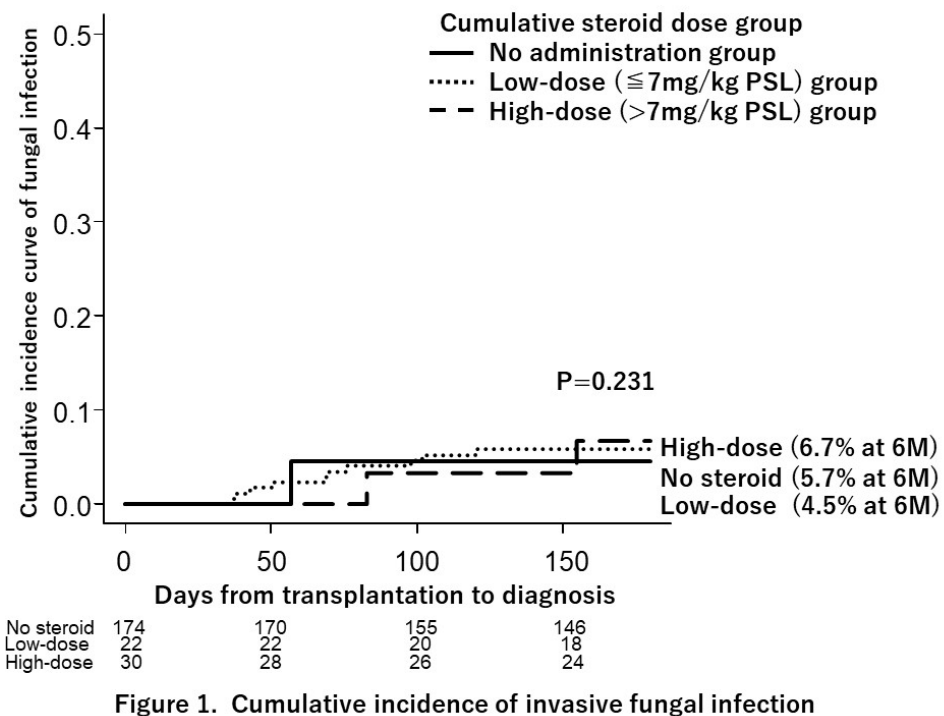

Figure 1

$338 \times 190 \mathrm{~mm}(96 \times 96$ DPI) 


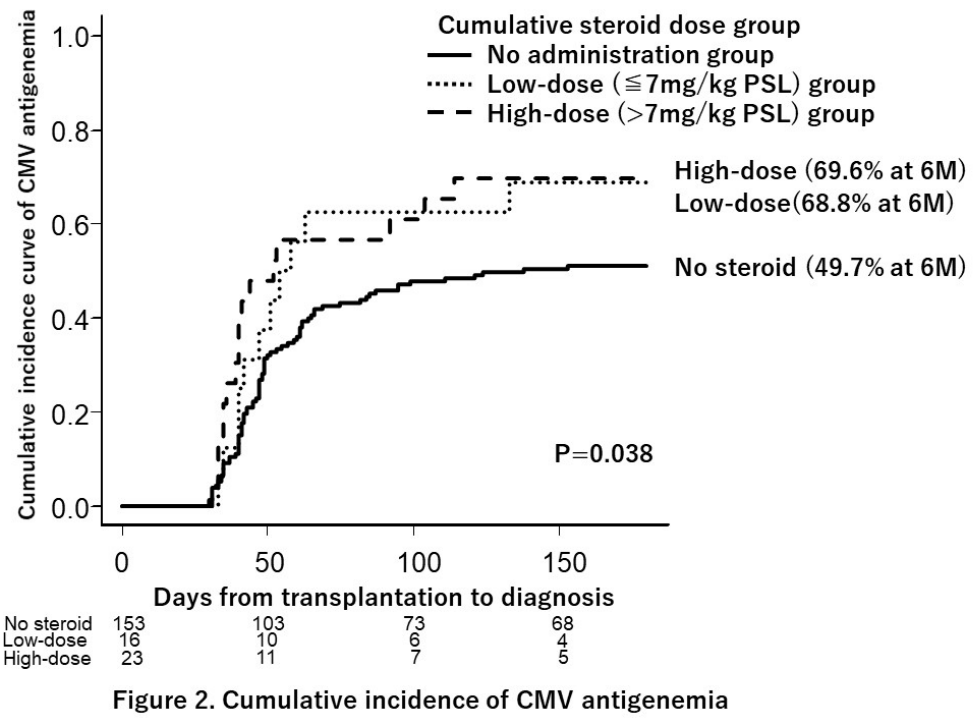

Figure 2

$338 \times 190 \mathrm{~mm}(96 \times 96$ DPI) 


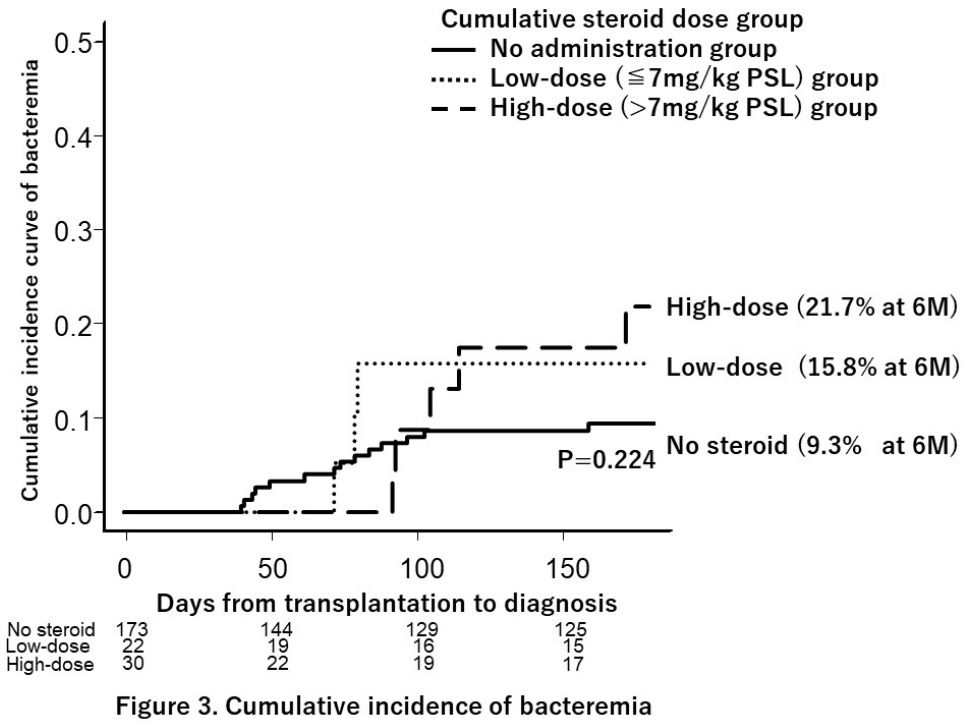

Figure 3

$338 \times 190 \mathrm{~mm}(96 \times 96$ DPI) 